\title{
A whole-mount in situ hybridization method for microRNA detection in Caenorhabditis elegans
}

\author{
YOSHIKI ANDACHI ${ }^{1,2}$ and YUJI KOHARA ${ }^{1,2}$ \\ ${ }^{1}$ Genetic Strains Research Center, National Institute of Genetics, Research Organization of Information and Systems, Mishima 411-8540, Japan \\ ${ }^{2}$ Department of Genetics, SOKENDAI (The Graduate University for Advanced Studies), Mishima 411-8540, Japan
}

\begin{abstract}
Whole-mount in situ hybridization (WISH) is an outstanding method to decipher the spatiotemporal expression patterns of microRNAs (miRNAs) and provides important clues for elucidating their functions. The first WISH method for miRNA detection was developed in zebrafish. Although this method was quickly adapted for other vertebrates and fruit flies, WISH analysis has not been successfully used to detect miRNAs in Caenorhabditis elegans. Here, we show a novel WISH method for miRNA detection in $C$. elegans. Using this method, mir-1 miRNA was detected in the body-wall muscle where the expression and roles of mir-1 miRNA have been previously elucidated. Application of the method to let-7 family miRNAs, let-7, mir-48, mir-84, and mir-241, revealed their distinct but partially overlapping expression patterns, indicating that miRNAs sharing a short common sequence were distinguishably detected. In pash-1 mutants that were depleted of mature miRNAs, signals of mir-48 miRNA were greatly reduced, suggesting that mature miRNAs were detected by the method. These results demonstrate the validity of WISH to detect mature miRNAs in $C$. elegans.
\end{abstract}

Keywords: C. elegans; miRNA; in situ hybridization; mir-1; let-7

\section{INTRODUCTION}

MicroRNAs (miRNAs) are endogenous RNAs of $~ 22$ nucleotides (nt) that play pivotal roles in the regulation of gene expression through binding to target mRNAs. The chief determinant of target recognition is base-pairing between an mRNA and a part of a miRNA: the nucleotides at positions 2-8 from the $5^{\prime}$ end of the miRNA, which is referred to as the seed sequence. A group of miRNAs that share a seed sequence is classified into a miRNA family. To date, there have been 434 miRNAs identified in Caenorhabditis elegans (Kozomara and Griffiths-Jones 2014), though the functions of most miRNAs remain elusive. In the canonical pathway of miRNA biogenesis, miRNA genes are initially transcribed into long primary-miRNAs (pri-miRNAs), which are subsequently processed into precursor-miRNAs (pre-miRNAs) in the nucleus. After transport to the cytoplasm, the premiRNAs are processed into mature miRNAs. As the expressions of miRNAs are transcriptionally controlled, the spatiotemporal expression patterns of miRNAs have been examined using animals transgenic for $g f p$ fusion with a miRNA gene promoter (Martinez et al. 2008). However, many lines of evidence indicate that several miRNAs are also regulated post-transcriptionally ( $\mathrm{Ha}$ and Kim 2014). Therefore, it is

Corresponding author: yandachi@nig.ac.jp

Article published online ahead of print. Article and publication date are at http://www.rnajournal.org/cgi/doi/10.1261/rna.054239.115. important to detect mature miRNAs in cells, tissues, and bodies.

Whole-mount in situ hybridization (WISH) is a natural choice for this purpose, and was first developed in zebrafish embryos (Wienholds et al. 2005). In this method, oligonucleotide probes including locked nucleic acids (LNAs) are effective for the acquisition of intense hybridization signals and increased specificity. WISH methods for miRNA detection soon became available for embryos of mouse, chicken, medaka, and fruit fly (Sokol and Ambros 2005; Ason et al. 2006; Darnell et al. 2006; Kloosterman et al. 2006). In addition, a significant improvement in the intensity of hybridization signals has been achieved by fixation of sectioned mouse tissues with 1-ethyl-3-(3-dimethylaminopropyl) carbodiimide (EDC), which reacts with phosphates at the $5^{\prime}$ end of miRNAs to introduce phosphoramidate linkages, resulting in all of the nucleotides of the miRNAs being accessible to probes for hybridization (Pena et al. 2009). Despite the efficient use of WISH methods, WISH analysis has still not been successfully used to detect miRNAs in C. elegans.

In this study, we developed a novel WISH method for miRNA detection in C. elegans at both embryonic and

(C) 2016 Andachi and Kohara This article is distributed exclusively by the RNA Society for the first 12 months after the full-issue publication date (see http://rnajournal.cshlp.org/site/misc/terms.xhtml). After 12 months, it is available under a Creative Commons License (Attribution-NonCommercial 4.0 International), as described at http://creativecommons.org/licenses/ by-nc/4.0/. 
post-embryonic stages by combining procedures, i.e., the use of LNA probes and EDC fixative, and the WISH methods for mRNA detection that we previously established in C. elegans (Tabara et al. 1996; Motohashi et al. 2006, 2015). To assess the new WISH method, we examined the expression patterns of mir-1 miRNA because the cell-autonomous roles of this miRNA have been elucidated. mir-1 miRNA is required to regulate synaptic transmission at neuromuscular junctions in body-wall muscle cells (Simon et al. 2008), which lie underneath the hypodermis in four longitudinal stripes over the length of the animal. To show distinguishable detection of miRNAs that share a seed sequence, we compared the expression patterns of let-7 family miRNAs, let-7, mir-48 (also known as lin-58), mir-84, and mir-241, of which deletion mutants are available and have been well studied for developmental phenotypes (Reinhart et al. 2000; Abbott et al. 2005). To confirm the detection of mature miRNAs, we conducted WISH analysis in pash-1 mutants. As pash-1 encodes an RNA-binding protein necessary for the processing of primiRNAs, pri-miRNAs accumulate, and mature miRNAs are depleted in pash-1 mutants (Denli et al. 2004; Lehrbach et al. 2012). The detection of mature miRNAs was also supported by the subcellular localization of WISH signals.

\section{RESULTS AND DISCUSSION}

\section{Critical parameters to obtain WISH signals in C. elegans}

During the search for WISH conditions that fit C. elegans, we noticed two critical parameters for better hybridization signals: the temperature of incubation with EDC to fix the animals and the concentration of proteinase to partially digest the fixed animals. There is a trade-off between these parameters. The fixation of mouse sectioned tissues with EDC is initially carried out by incubation at $25^{\circ} \mathrm{C}$ (Pena et al. 2009), which is subsequently increased to $50^{\circ} \mathrm{C}$ to achieve near-complete phosphoramide bond formation in a shorter time (Renwick et al. 2013). Cross-linking of miRNAs with EDC for Northern blotting also shows that increasing the reaction temperature up to $60^{\circ} \mathrm{C}$ improves miRNA detection (Pall et al. 2007). More cross-linking at higher temperatures must lead to more retention of miRNAs, leading to stronger hybridization signals. However, cross-linking with EDC acts not only on miRNAs but also on proteins to form peptide bonds, which make the proteins resistant to proteinase (Sung et al. 2003; Renwick et al. 2013). As the surfaces of C. elegans larvae and adults are overlaid with cuticle layers composed of collagens, the layers have to be partially digested by proteinase so that WISH reagents, such as probes, can penetrate inward. More fixation inhibits this process further and necessitates more proteinase for proper digestion. For this reason, we evaluated the incubation temperature with EDC in combination with subsequent digestion by various concentrations of proteinase. As a result, we found that optimized conditions to generate intense signals with animals were fixation with $\mathrm{EDC}$ at $60^{\circ} \mathrm{C}$ and subsequent digestion by proteinase $\mathrm{K}$ at $2 \mathrm{mg} / \mathrm{mL}$ : This concentration is so high that unfixed animals are easily dissolved. For embryos, slight modification was made to treat the tough eggshells.

\section{WISH signals of mir-1 miRNA were detected in muscle tissues}

The expression patterns of mir-1 miRNA were examined by the WISH method throughout all developmental stages. Staining for mir-1 miRNA was observed in the body-wall muscle at the adult stage (Fig. 1A-C). Additionally, mir-1 miRNA was detected in the anal depressor muscle (Fig. 1A) and the pharynx (Fig. 1A,B), which is a muscular tube used to suck food. The miRNA was also detected in sex-specific muscles, i.e., the vulval muscle in hermaphrodites (Fig. 1C) and the diagonal muscle in males (Fig. 1B). Analyses of larvae by the method also gave signals in these muscles at each of the four larval stages (Fig. 1D-G). Pharyngeal signals were detected in embryos at the 500-cell stage and later (Fig. $1 \mathrm{H}-\mathrm{K}$ ). The expression patterns of mir-1 miRNA are consistent with tissues where the $g f p$ reporter driven by the promoter of the mir-1 gene is expressed (Supplemental Fig. S1; Martinez et al. 2008; Simon et al. 2008). Furthermore, we confirmed that the signals of mir-1 miRNA were lost in mir-1 deletion mutants (Supplemental Fig. S2). These results are in agreement with the cell-autonomous roles of mir-1 miRNA in the body-wall muscle, and suggest additional roles of the miRNA in the other muscle tissues.

\section{WISH signals of let-7 family miRNAs were detected in distinct but partially overlapping tissues}

The expression patterns of four let-7 family miRNAs, let-7, mir-48, mir-84, and mir-241, were compared at the fourth larval (L4) stage (Supplemental Fig. S3), as Northern blot analyses show that mature forms of all the miRNAs start to accumulate at the mid-larval stage and reach exceedingly high levels at the L4 stage (Reinhart et al. 2000; Bracht et al. 2004; Abbott et al. 2005). In the head, staining in the pharynx was observed for let-7 and mir-84 miRNAs, whereas staining in neurons of the head ganglia was observed for all of the miRNAs (Fig. 2A,D,G,J). WISH analysis of every miRNA showed staining in the vulva (Fig. 2B,E,H,K). Signals of let-7, mir-48, and mir-241 miRNAs were detected in the rectum (Fig. 2C,F,I,L). mir-48 miRNA was also detected in seam cells (Fig. 2M). Consistent with the expressions of all the miRNAs in the vulva, let-7 mutants and mir-48 mir-241; mir-84 triple mutants show a phenotype of bursting through the vulva (Reinhart et al. 2000; Abbott et al. 2005), and the activity of let-7 miRNA is cell-autonomously required to rescue the bursting phenotype in let-7 mutants (Ecsedi et al. 2015).

To confirm that these overlapping expressions of the let-7 family miRNAs are not due to cross-hybridization among them, the expressions of the miRNAs were examined in their 

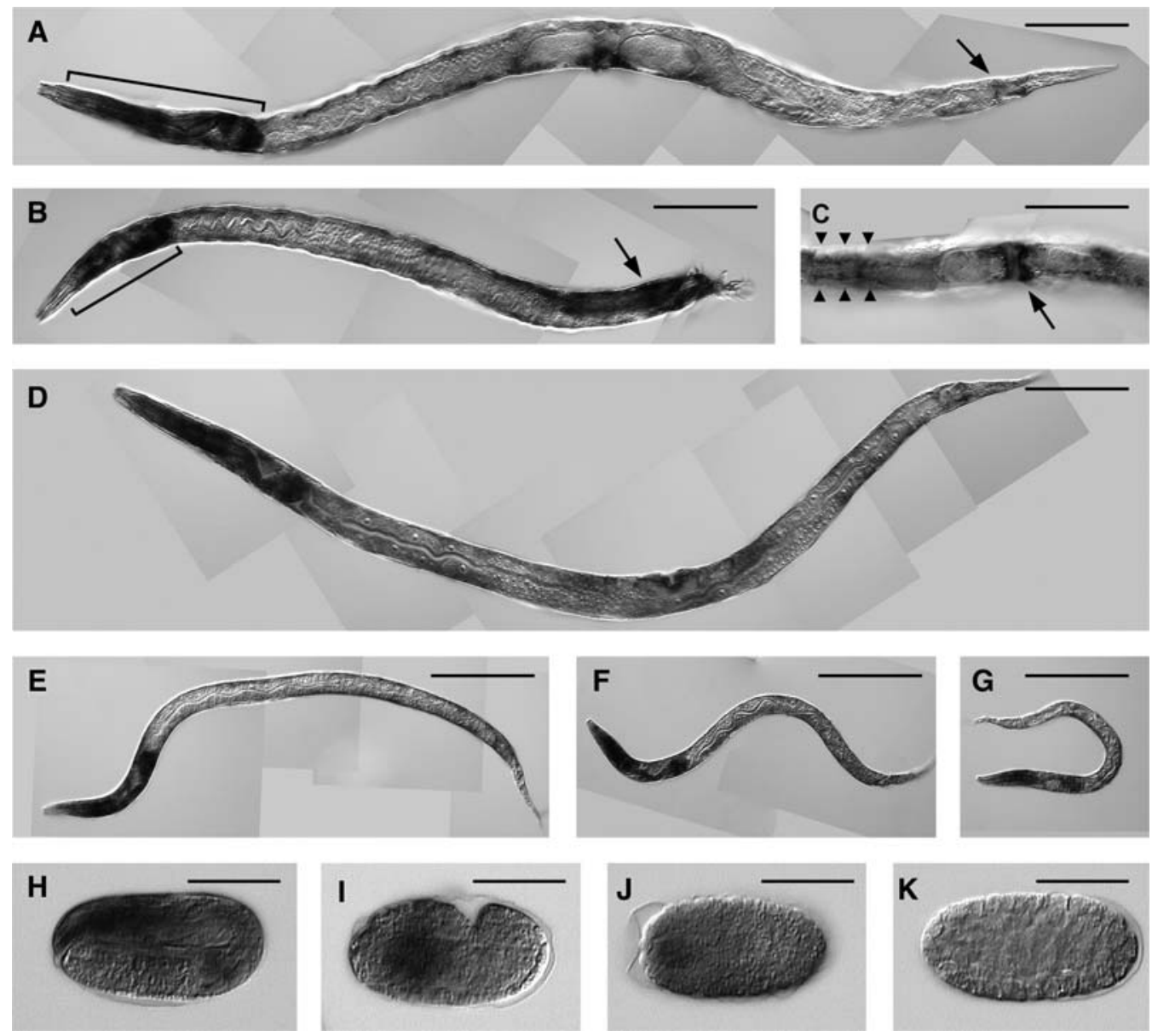

FIGURE 1. WISH analysis for detection of mir-1 miRNA. Images show an adult hermaphrodite $(A)$, an adult male $(B)$, and a ventral view of the vulva of an adult hermaphrodite $(C)$. The brackets designate the pharynx $(A, B)$. The arrows indicate the anal depressor muscle $(A)$, the diagonal muscle $(B)$, and the vulval muscle $(C)$. The arrowheads show the body-wall muscle $(C)$. Larvae are at the L4 $(D), \mathrm{L} 3(E), \mathrm{L} 2(F)$, and L1 $(G)$ stages. Embryos are at the fourfold $(H), 1.5$-fold $(I), 500$-cell $(J)$, and 200-cell $(K)$ stages. Scale bars, $100 \mu \mathrm{m}(A-G)$ and $30 \mu \mathrm{m}(H-K)$.

deletion mutants. Using the following three strains of double deletion mutants, mir-48 mir-241, mir-48; mir-84, and mir241; mir-84, loss of the expressions of mir-48, mir-84, and mir-241 miRNAs were found only in the strains that had the deletion of the corresponding miRNA genes (Supplemental Fig. S4A-L). As to let-7, lethality associated with the vulval bursting made it difficult to collect a large number of mutant animals for WISH analysis. Therefore, we utilized a deletion mutant strain whose lethality was rescued by the let-7 transgene. As the transgene was generated as an extrachromosomal array and the array was unstably inherited, transgenic animals segregated progeny with or without the transgene. The vulval bursting phenotype was an indicator that animals had lost the transgene and had been fixed just after the incidence of bursting because the extrusion of internal organs through the rupture leads to severe damage to the body. While animals with a normal vulva showed staining, animals with the phenotype gave no signal of let-7 miRNA (Supplemental Fig. S4M,N). These results indicate that the WISH signals of the let-7 family miRNAs are miRNA specific.

\section{miRNAs in the cytoplasm, but not pri-miRNAs, were detected by the WISH method}

Precursors of miRNAs also contain complementary sequences to probes for the miRNAs. To inspect miRNA forms detected by our method, WISH analysis was conducted in temperature-sensitive pash-1(mj100) mutants, which were depleted of mature miRNAs after cultivation at the restrictive temperature (Lehrbach et al. 2012). WISH signals of mir-48 miRNA were considerably weaker in pash-1 mutants when grown under the restrictive conditions than in control animals, which were pash-1 mutants under permissive conditions and wild-type animals under restrictive conditions (Fig. 3A-C). Faint staining was predominantly observed in the cytoplasm of the pash-1 mutants (Fig. 3A), suggesting that mir-48 pri-miRNAs, which accumulated in the nucleus, hardly contributed to WISH signals. One explanation for this result is that the pri-miRNAs were not retained in the fixed animals, because pri-miRNAs contain a $5^{\prime}$-cap structure (Bracht et al. 2004), and the structure prevented the 

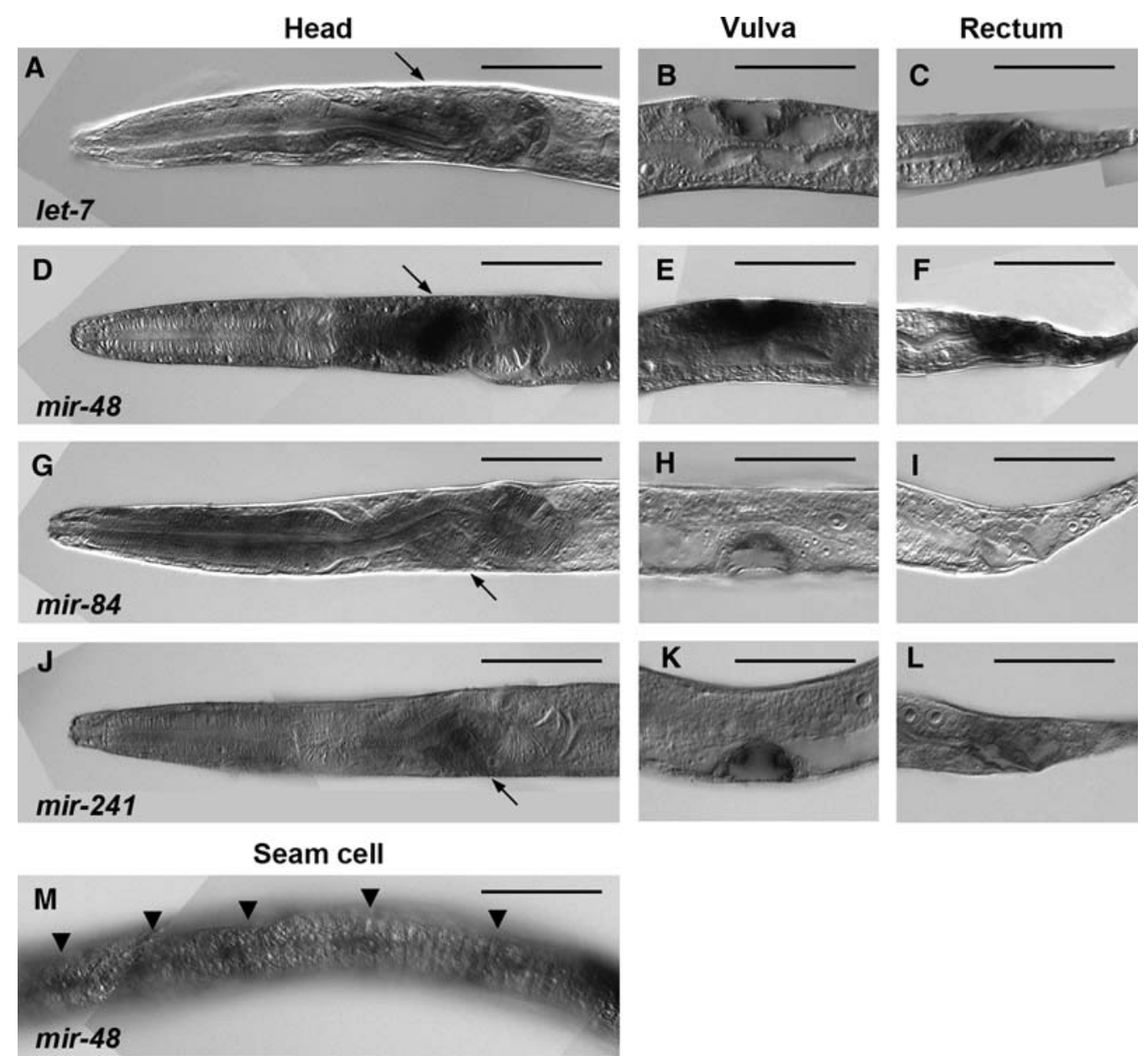

FIGURE 2. WISH analysis for detection of let-7 family miRNAs at the L4 stage. The family members are let-7 (A-C), mir-48 (D-F,M), mir-84 (G-I), and mir-241 $(J-L)$. Images show the head region $(A, D, G, J)$, the vulva $(B, E, H, K)$, the rectum $(C, F, I, L)$, and seam cells $(M)$. The arrows indicate neurons of the head ganglia $(A, D, G, J)$. The arrowheads point to seam cells $(M)$. Whole-body images corresponding to these partial images are shown in Supplemental Figure S4. Scale bars, $50 \mu \mathrm{m}$.

formation of phosphoramidite linkages with EDC, which reacts with free phosphates at the $5^{\prime}$-end of miRNAs.

The subcellular localization of WISH signals can be clearly visualized by staining with fluorescent dye. Fluorescent signals of mir-48 miRNA were detected mostly in the cytoplasm of the same tissues as chromogenic signals (Fig. 4AC; Supplemental Fig. S5A-C). Fluorescent signals of let-7, mir-84, and mir-241 miRNAs, however, were obscure due to the low signal-background ratio (Fig. 4D-F; Supplemental Fig. S5D-F, data not shown). As mir-48 miRNA is the most abundant among the let-7 family miRNAs, as revealed by high-throughput sequencing analysis of $C$. elegans miRNAs (Kato et al. 2009), it is likely that the amount of the three miRNAs was not enough to obtain intense fluorescent signals. Although mir-1 miRNA is one of the most abundant miRNAs revealed by sequencing analysis (Kato et al. 2009), fluorescent signals of mir-1 miRNA were also obscure in muscle tissues except for the pharynx (data not shown). To address the issue that the amount of miRNAs is pivotal to obtain intense fluorescent signals, WISH analysis was conduct- ed in animals containing a let-7 transgene, which can provide a large amount of let-7 miRNAs. Intense fluorescent signals of let-7 miRNA were detected in the transgenic animals and were almost all localized in the cytoplasm (Fig. 4G-I; Supplemental Fig. S5G-I). These results suggest that increasing the amount of miRNAs by a transgenic strategy is a powerful way to obtain fluorescent high-resolution signals of the miRNAs.

Although we cannot rule out the possibility that premiRNAs in the cytoplasm partially contributed to WISH signals, these results suggest that miRNAs in the cytoplasm, which were possibly mature miRNAs, and not pri-miRNAs in the nucleus, were detected by the method.

In this report, we presented a novel WISH method to detect mature miRNAs in C. elegans. The validity of the method was evaluated by the detection of mir-1 miRNA and let-7 family miRNAs in the tissues where the roles of these miRNAs have been elucidated, and by a lack of detection of the miRNAs in deletion mutants. The detection of mature miRNAs by the method was strongly suggested by the reduction of the WISH signals of mir-48 miRNA in 

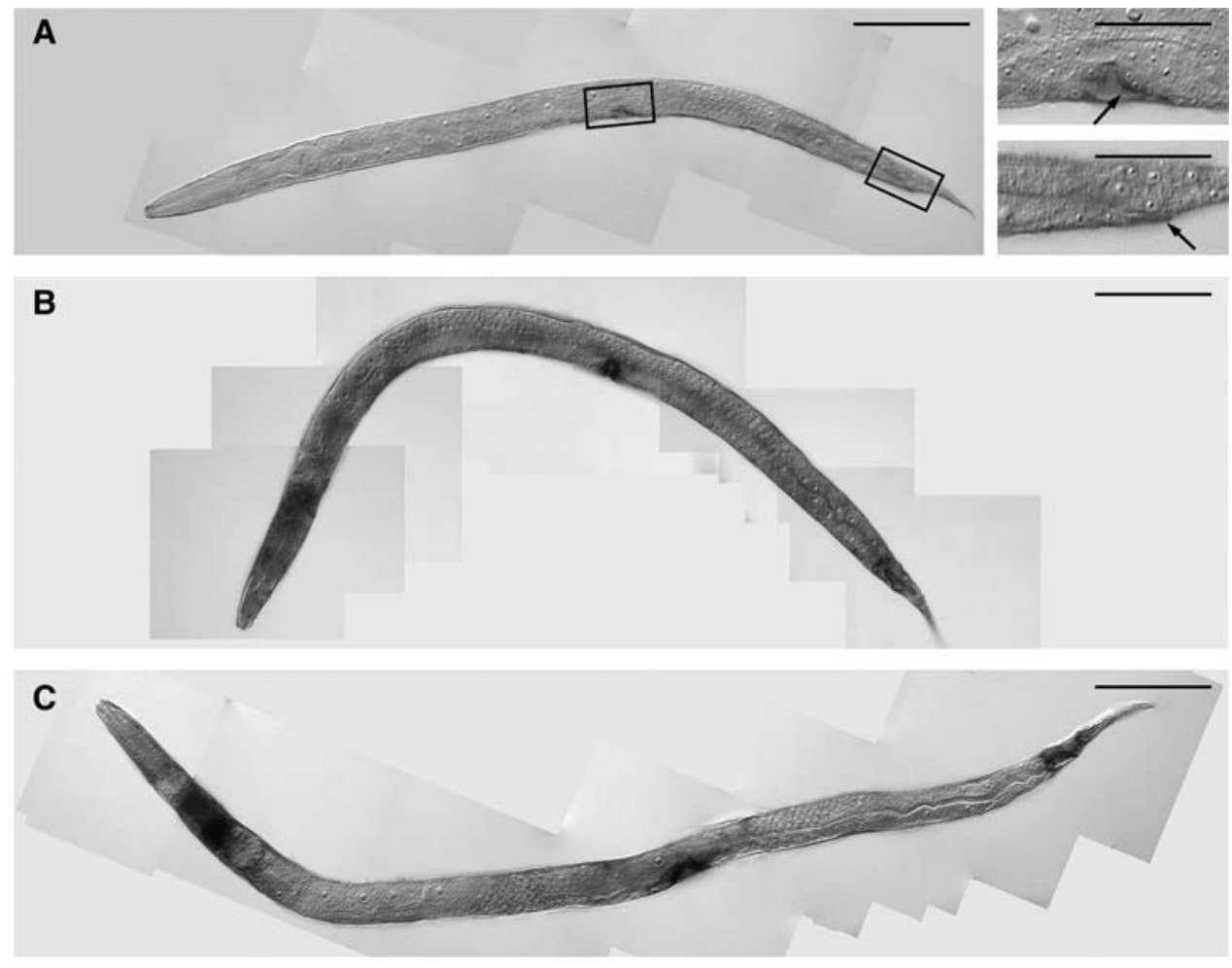

FIGURE 3. WISH analysis for detection of mir-48 miRNA in temperature-sensitive pash-1 mutants at the L4 stage. Genotypes are pash- $1(A, B)$ and wild-type $(C)$. Animals were grown under restrictive conditions $(A, C)$ and under permissive conditions $(B)$. Images on the right in $A$ show magnified views of the boxed regions in the image on the left, and the arrows indicate nuclei of the vulva (top) and the rectum (bottom). Scale bars, $100 \mu \mathrm{m}(A-C)$ and $30 \mu \mathrm{m}$ (magnified images in $A$ ).

pash-1 mutants, and by localization of the fluorescent signals of the miRNA exclusively in the cytoplasm. The WISH method will be not only useful for miRNA research in C. elegans, but the strategy can be adapted for WISH methods to detect miRNAs in other organisms.

\section{MATERIALS AND METHODS}

\section{Caenorhabditis elegans strains and culture}

The following strains and mutant alleles were used in this study: wild-type Bristol N2, mir-1(n4102) I, pash-1(mj100) I, lin-58 mir241(nDf51) V, lin-58(n4097) V; mir-84(n4037) X, mir-241(n4315) $\mathrm{V}$; mir-84(n4037) X, let-7(mn112) unc-3(e151) X, and maIs251 [mir-1p::gfp]. Animals were grown at $20^{\circ} \mathrm{C}$ as previously described (Andachi 2008). To prepare animals under the restrictive conditions, pash-1 mutants and wild-type controls were grown from eggs at $16^{\circ} \mathrm{C}$ and subsequently at $25^{\circ} \mathrm{C}$ for $20 \mathrm{~h}$, which spanned the period from mid to late larval stages. The developmental stage of animals was assessed by gonad morphology.

\section{Whole-mount in situ hybridization analysis of larvae and adults}

Synchronized populations of larvae or adults were prepared by cultivation of eggs that were collected by hypochlorite treatment of adult hermaphrodites. The animals were usually reared in liquid S medium containing Escherichia coli strain OP50 or sometimes on NGM plates: Both cultivations gave essentially the same results. The animals were cleaned by the sucrose flotation procedure and chilled on ice. Approximately $300 \mu \mathrm{L}$ of the packed animals was transferred to a new 2-mL siliconized tube. In the following procedures, incubation was carried out in $1 \mathrm{~mL}$ of a specified solution at room temperature for $2 \mathrm{~min}$ with continuous rotation of the tube, and was terminated by centrifugation at $3000 \mathrm{rpm}$ for $1 \mathrm{~min}$ followed by the removal of supernatant fluid by pipetting, unless otherwise indicated. The animals were incubated in DENT $(80 \%$ methanol $+20 \%$ dimethyl sulfoxide) at $-20^{\circ} \mathrm{C}$ for $10 \mathrm{~min}$. The animals were rehydrated at $4^{\circ} \mathrm{C}$ through a graded series of $100 \%$ methanol, 90\% methanol $+10 \%$ Fixative-phosphate $(80 \mathrm{mM}$ HEPES [pH 6.9], $1.6 \mathrm{mM} \mathrm{MgSO}_{4}, 0.8 \mathrm{mM}$ EGTA, and $100 \mathrm{mM} \mathrm{NaCl}$, $3.7 \%$ formaldehyde), $70 \%$ methanol $+30 \%$ Fixative-phosphate, $50 \%$ methanol $+50 \%$ Fixative-phosphate, $30 \%$ methanol $+70 \%$ Fixative-phosphate, and 100\% Fixative-phosphate, and then fixed in Fixative-phosphate at $4^{\circ} \mathrm{C}$ for $20 \mathrm{~min}$. The animals were washed three times in EDC buffer (130 mM 1-methylimidazole [pH 8], 300 $\mathrm{mM} \mathrm{NaCl}$ ), and then incubated in freshly prepared EDC Fixative (160 mM EDC, $130 \mathrm{mM}$ 1-methylimidazole [pH 8], $300 \mathrm{mM}$ $\mathrm{NaCl})$ at $60^{\circ} \mathrm{C}$ for $1 \mathrm{~h}$. The animals were washed three times in $1 \times \mathrm{BO}_{3}$ (25 mM sodium borate [pH 9]), and then incubated in $1 \times \mathrm{BO}_{3}$ with $10 \mathrm{mM}$ dithiothreitol (DTT) for $20 \mathrm{~min}$. The animals were washed three times in $1 \times \mathrm{BO}_{3}$, and then incubated in $1 \times \mathrm{BO}_{3}$ with $0.6 \% \mathrm{H}_{2} \mathrm{O}_{2}$ for $20 \mathrm{~min}$. The animals were washed three times in PBT (PBS [137 mM NaCl, $2.7 \mathrm{mM} \mathrm{KCl}, 4.3 \mathrm{mM} \mathrm{Na}_{2} \mathrm{HPO}_{4}, 1.5 \mathrm{mM}$ 

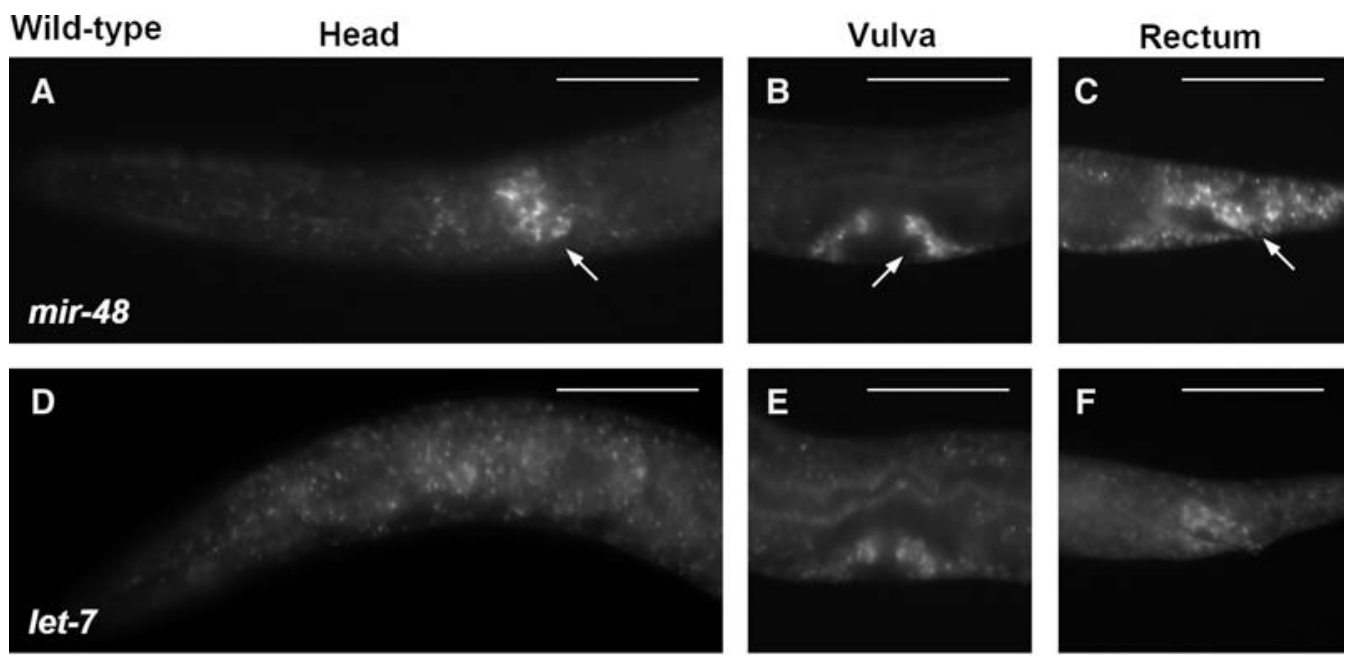

\section{let-7; Ex[let-7]}
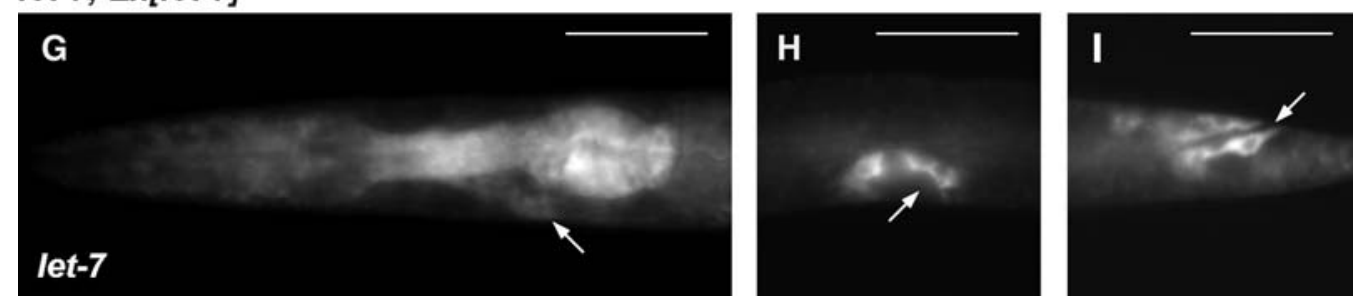

FIGURE 4. Fluorescent WISH analysis for detection of let-7 family miRNAs at the L4 stage. The family members are mir-48 $(A-C)$ and let-7 $(D-I)$. Genotypes are wild type $(A-F)$ and let-7; Ex [let-7] $(G-I)$. Images show the head region $(A, D, G)$, the vulva $(B, E, H)$, and the rectum $(C, F, I)$. The white arrows in $(A-C, G-I)$ indicate fluorescent signals in the cytoplasm that surround nuclei, which are observed as circles without staining. Color images corresponding to this figure are shown in Supplemental Figure S5. Scale bars, $50 \mu \mathrm{m}$.

$\left.\mathrm{KH}_{2} \mathrm{PO}_{4}\right], 0.1 \%$ Tween-20), and then digested with proteinase $\mathrm{K}$ at a concentration of $2 \mathrm{mg} / \mathrm{mL}$ in PBT with $1 \% \beta$-mercaptoethanol $(\beta-\mathrm{ME})$ at $37^{\circ} \mathrm{C}$ for $20 \mathrm{~min}$. The animals were washed three times in PBS, and then fixed in Fixative ( $80 \mathrm{mM}$ HEPES [ $\mathrm{pH} 6.9$ ], $1.6 \mathrm{mM} \mathrm{MgSO}$, $0.8 \mathrm{mM}$ EGTA, PBS, 3.7\% formaldehyde) for $20 \mathrm{~min}$. The animals were finally washed three times in PBS. Aliquots of the animals suspended in PBS were allowed to stick to wells on Teflon printed diagnostic slides that had been coated with polyL-lysine. The animals on slides were dehydrated through a graded series of $30 \%$ ethanol $+70 \%$ PBS, $50 \%$ ethanol $+50 \%$ PBS, $70 \%$ ethanol $+30 \%$ PBS, 90\% ethanol $+10 \%$ distilled water, and $100 \%$ ethanol for $5 \mathrm{~min}$ each. The samples could be stored in ethanol at $-20^{\circ} \mathrm{C}$ for at least $1 \mathrm{mo}$.

In the following procedures, samples on slides were immersed in a specified solution at room temperature for $5 \mathrm{~min}$, unless otherwise indicated. The animals were rehydrated through a graded series of ethanol with $24 \mathrm{mM} \mathrm{HCl}, 90 \%$ ethanol $+10 \%$ distilled water, $70 \%$ ethanol $+30 \%$ PBS, 50\% ethanol $+50 \%$ PBS, 30\% ethanol + $70 \%$ PBS, and $100 \%$ PBS. After excess fluid on the slides was wiped off, the animals in each well were covered with $100 \mu \mathrm{L}$ of proteinase $\mathrm{K}$ at a concentration of $0.5 \mathrm{mg} / \mathrm{mL}$ in PBT with $1 \% \beta$-ME, and incubated at $37^{\circ} \mathrm{C}$ for $20 \mathrm{~min}$ in a moist chamber. The animals were washed in PBS twice, and then fixed in Fixative for $20 \mathrm{~min}$. The animals were washed in PBS twice, and then incubated in PBS containing glycine at a concentration of $2 \mathrm{mg} / \mathrm{mL}$. The animals were incubated in a series of PBS for $5 \mathrm{~min}, 50 \%$ PBS + 50\% hybridization buffer (50\% deionized formamide, $750 \mathrm{mM} \mathrm{NaCl}, 75 \mathrm{mM}$ sodium citrate $[\mathrm{pH} 7.0], 100 \mu \mathrm{g} / \mathrm{mL}$ heparin, and 2\% Blocking Reagent
[Roche]) for $10 \mathrm{~min}$, and hybridization buffer for $10 \mathrm{~min}$. For prehybridization, the animals in each well were covered with $100 \mu \mathrm{L}$ of hybridization buffer and incubated for $1 \mathrm{~h}$ in a moist chamber at a hybridization temperature suitable for each probe. After the buffer was exchanged with $100 \mu \mathrm{L}$ of hybridization buffer containing $10 \mathrm{nM}$ heat-denatured probes, the animals were further incubated for $2 \mathrm{~h}$ in a moist chamber at the same hybridization temperature. Probes were $5^{\prime}$ digoxigenin-labeled oligodeoxynucleotides containing LNAs (Nippon Gene Material). The hybridization temperature for each probe was experimentally determined as follows. A hybridization temperature was tentatively set at $20^{\circ} \mathrm{C}-25^{\circ} \mathrm{C}$ below the melting temperature of the probe that was calculated by the manufacturer. WISH experiments were carried out at the hybridization temperature and at slightly different (both higher and lower) hybridization temperatures. Among them, we chose a hybridization temperature at which tissue-specific signals were detected in wildtype animals and the signals were lost in their deletion mutants. See Table 1 for the nucleotide sequences and the hybridization temperatures of probes.

The animals on the slides were immersed in hybridization buffer at the same hybridization temperature with continuous shaking for 10 min twice, and in $0.2 \times$ SSC $(150 \mathrm{mM} \mathrm{NaCl}, 15 \mathrm{mM}$ sodium citrate $[\mathrm{pH} 7.0])$ in the same way twice. For blocking, after washing in TNT (100 mM Tris [pH 7.5], $150 \mathrm{mM} \mathrm{NaCl}, 0.5 \%$ Tween-20) twice, the animals in each well were covered with $100 \mu \mathrm{L}$ of TNB $(100 \mathrm{mM}$ Tris [pH 7.5], $150 \mathrm{mM} \mathrm{NaCl}, 0.5 \%$ Blocking Reagent [TSA Plus Cy3 Kit, PerkinElmer]) and incubated for $30 \mathrm{~min}$ in a moist chamber. For staining with fluorescent dye, after the buffer was exchanged 
TABLE 1. The nucleotide sequences and the hybridization temperatures of probes

\begin{tabular}{|c|c|c|}
\hline microRNA & Sequence & Hybridization temperature \\
\hline mir-1 & $5^{\prime}$-(DIG)TACATACTTCTTTTACATTCCA-3' & $50^{\circ} \mathrm{C}$ \\
\hline let-7 & 5'-(DIG)AACTATACAACCTACTACCTCA-3' & $58^{\circ} \mathrm{C}$ \\
\hline mir-48 & 5'-(DIG)TCGCATCTACTGAGCCTACCTCA-3' & $58^{\circ} \mathrm{C}$ \\
\hline mir-84 & 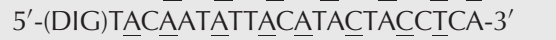 & $46^{\circ} \mathrm{C}$ \\
\hline mir-241 & 5'-(DIG)TCA & $54^{\circ} \mathrm{C}$ \\
\hline
\end{tabular}

(DIG) shows 5'-labeled digoxigenin. Locked nucleic acids (LNAs) are indicated by underlines. indicated. The eggs were rehydrated through a graded series of ethanol with $0.6 \% \quad \mathrm{H}_{2} \mathrm{O}_{2}, \quad 90 \%$ ethanol $+10 \% \quad \mathrm{TN}$ (100 mM Tris [pH 7.5], $150 \mathrm{mM} \mathrm{NaCl}$ ), $70 \%$ ethanol $+30 \%$ TN, $50 \%$ ethanol + $50 \%$ TN, 30\% ethanol $+70 \% \mathrm{TN}$, and $100 \%$ TN. After washing in EDC buffer twice, the eggs on slides were immersed in freshly prepared EDC Fixative preheated at $60^{\circ} \mathrm{C}$, and then incubated at $60^{\circ} \mathrm{C}$ for $20 \mathrm{~min}$. After the eggs were washed in PBT twice and excess fluid on the slides was with $100 \mu \mathrm{L}$ of TNB containing Anti-Digoxigenin-POD Fab fragments (Roche), the animals were further incubated for $1 \mathrm{~h}$ in a moist chamber, and then washed in TNT with continuous shaking for 10 min four times. Fluorescent staining was carried out using a TSA Plus Cy3 Kit following the manufacturer's instructions. For staining with chromogenic substrate, the blocked animals in each well were covered with $100 \mu \mathrm{L}$ of TNB containing Anti-Digoxigenin-AP Conjugate (Roche), incubated for $2 \mathrm{~h}$ in a moist chamber, and then washed in TNT with continuous shaking for $10 \mathrm{~min}$ four times. Chromogenic staining was carried out using a DIG Nucleic Acid Detection Kit (Roche) following the manufacturer's instructions, except that incubation in color substrate solution was carried out until staining appeared in the samples: The range of incubation time was from a few hours to a few days.

\section{Whole-mount in situ hybridization analysis of embryos}

Caenorhabditis elegans eggs were collected by hypochlorite treatment of adult hermaphrodites. Approximately $100 \mu \mathrm{L}$ of the packed eggs was transferred to a new $1.5-\mathrm{mL}$ siliconized tube. The following procedures were carried out at room temperature, unless otherwise indicated. To remove eggshells, the eggs were mixed with $100 \mu \mathrm{L}$ of yatalase (Takara Bio) at a concentration of $15 \mathrm{mg} / \mathrm{mL}$ in Embryo Handling buffer (300 mM mannitol, $50 \mathrm{mM}$ HEPES [pH 7.2], $10 \mathrm{mM} \mathrm{NaCl}, 10 \mathrm{mM} \mathrm{MgCl} 2,1 \mathrm{mM}$ EGTA, $2 \mathrm{mM} \mathrm{NH} \mathrm{NO}_{3}$, $0.1 \%$ gelatin) and vortexed for $75 \mathrm{sec}$. The eggs were washed three times in $1 \mathrm{~mL}$ of Embryo Handling buffer, which was removed by pipetting after centrifugation at $3000 \mathrm{rpm}$ for $1 \mathrm{~min}$, and washed once in $1 \mathrm{~mL}$ of basal Embryo Handling buffer ( $300 \mathrm{mM}$ mannitol, $50 \mathrm{mM}$ HEPES [pH 7.2], $10 \mathrm{mM} \mathrm{NaCl}, 10 \mathrm{mM} \mathrm{MgCl}$ ). Aliquots of the egg suspension in basal Embryo Handling buffer were allowed to stick to wells on Teflon printed diagnostic slides that had been coated with poly-L-lysine. The eggs on slides were immersed in methanol chilled at $-20^{\circ} \mathrm{C}$ for $10 \mathrm{~min}$, and rehydrated at room temperature through a graded series of $100 \%$ methanol, $90 \%$ methanol $+10 \%$ Fixative-phosphate, $70 \%$ methanol $+30 \%$ Fixative-phosphate, $50 \%$ methanol $+50 \%$ Fixative-phosphate, $30 \%$ methanol + $70 \%$ Fixative-phosphate, and 100\% Fixative-phosphate for $5 \mathrm{~min}$ each, and then fixed in Fixative-phosphate for $20 \mathrm{~min}$. The eggs were dehydrated through a graded series of $30 \%$ ethanol $+70 \%$

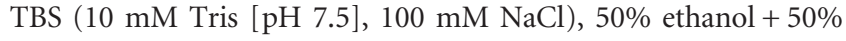
TBS, $70 \%$ ethanol $+30 \%$ TBS, $90 \%$ ethanol $+10 \%$ TBS, and $100 \%$ ethanol for $5 \mathrm{~min}$ each. The samples could be stored in ethanol at $-20^{\circ} \mathrm{C}$ for at least $1 \mathrm{mo}$.

In the following procedures, samples on slides were immersed in a specified solution at room temperature for 5 min unless otherwise wiped off, the eggs in each well were covered with $100 \mu \mathrm{L}$ of proteinase $\mathrm{K}$ at a concentration of $2 \mathrm{mg} / \mathrm{mL}$ in PBT with $1 \% \beta$-ME, and incubated at $37^{\circ} \mathrm{C}$ for $20 \mathrm{~min}$ in a moist chamber. After washing in PBS twice, the eggs were fixed in Fixative for $20 \mathrm{~min}$. After washing in PBS twice, the eggs were incubated in PBS containing glycine at a concentration of $2 \mathrm{mg} / \mathrm{mL}$. Hybridization was carried out by the same procedure for larvae and adults.

\section{Transgenics}

Caenorhabditis elegans genomic DNA corresponding to nucleotides 11,422-15,339 of cosmid C05G5 (accession number: Z70203) was PCR-amplified to produce a plasmid clone of the let-7 gene, which was verified by DNA sequencing. let-7 plasmid DNA at $5 \mu \mathrm{g} / \mathrm{mL}$ was transformation marker plasmid, K10C3.4 $4^{\text {promoter }}::$ rp:::unc-54 $4^{3^{\prime} U T R}$ (Andachi 2008), at $20 \mu \mathrm{g} / \mathrm{mL}$, and the mixture was injected into adult gonads of the wild-type strain to generate an extrachromosomal array. The array was crossed into the let-7 background.

\section{Microscopy}

Images of chromogenically stained samples were captured using an Axioplan2 microscope (Carl Zeiss) equipped with Nomarski differential interference contrast and a DXC-970MD CCD color camera (Sony), and processed using Photoshop (Adobe Systems) software. Images of fluorescently stained samples and anesthetized animals with the $g f p$ reporter were captured using an Axioplan2 microscope equipped with epifluorescence optics and an ORCA-ER CCD camera (Hamamatsu Photonics), and processed using Photoshop software.

\section{SUPPLEMENTAL MATERIAL}

Supplemental material is available for this article.

\section{ACKNOWLEDGMENTS}

The mutant alleles used in this work were provided by the Caenorhabditis Genetics Center, which is funded by the National Institutes of Health Office of Research Infrastructure Programs (P40 OD010440). We thank members of the Kohara laboratory for discussion and critical comments. This work was supported by the Japan Society for the Promotion of Science KAKENHI grant numbers 22241047 and 25250025 to Y.K.

Received August 28, 2015; accepted April 1, 2016. mixed with pBluescript II KS+ DNA at $75 \mu \mathrm{g} / \mathrm{mL}$ and DNA of a 


\section{REFERENCES}

Abbott AL, Alvarez-Saavedra E, Miska EA, Lau NC, Bartel DP, Horvitz HR, Ambros V. 2005. The let-7 microRNA family members mir-48, mir-84, and mir-241 function together to regulate developmental timing in Caenorhabditis elegans. Dev Cell 9: 403-414.

Andachi Y. 2008. A novel biochemical method to identify target genes of individual microRNAs: identification of a new Caenorhabditis elegans let-7 target. RNA 14: 2440-2451.

Ason B, Darnell DK, Wittbrodt B, Berezikov E, Kloosterman WP, Wittbrodt J, Antin PB, Plasterk RH. 2006. Differences in vertebrate microRNA expression. Proc Natl Acad Sci 103: 14385-14389.

Bracht J, Hunter S, Eachus R, Weeks P, Pasquinelli AE. 2004. Transsplicing and polyadenylation of let-7 microRNA primary transcripts. RNA 10: 1586-1594.

Darnell DK, Kaur S, Stanislaw S, Konieczka JH, Yatskievych TA, Antin PB. 2006. MicroRNA expression during chick embryo development. Dev Dyn 235: 3156-3165.

Denli AM, Tops BB, Plasterk RH, Ketting RF, Hannon GJ. 2004. Processing of primary microRNAs by the microprocessor complex. Nature 432: 231-235.

Ecsedi M, Rausch M, Großhans H. 2015. The let-7 microRNA directs vulval development through a single target. Dev Cell 32: 335-344.

Ha M, Kim VN. 2014. Regulation of microRNA biogenesis. Nat Rev Mol Cell Biol 15: 509-524.

Kato M, de Lencastre A, Pincus Z, Slack FJ. 2009. Dynamic expression of small non-coding RNAs, including novel microRNAs and piRNAs/ 21U-RNAs, during Caenorhabditis elegans development. Genome Biol 10: R54.

Kloosterman WP, Wienholds E, de Bruijn E, Kauppinen S, Plasterk RH. 2006. In situ detection of miRNAs in animal embryos using LNAmodified oligonucleotide probes. Nat Methods 3: 27-29.

Kozomara A, Griffiths-Jones S. 2014. miRBase: annotating high confidence microRNAs using deep sequencing data. Nucleic Acids Res 42: D68-D73.

Lehrbach NJ, Castro C, Murfitt KJ, Abreu-Goodger C, Griffin JL, Miska EA. 2012. Post-developmental microRNA expression is required for normal physiology, and regulates aging in parallel to insulin/IGF-1 signaling in C. elegans. RNA 18: 2220-2235.

Martinez NJ, Ow MC, Reece-Hoyes JS, Barrasa MI, Ambros VR, Walhout AJM. 2008. Genome-scale spatiotemporal analysis of
Caenorhabditis elegans microRNA promoter activity. Genome Res 18: 2005-2015.

Motohashi T, Tabara H, Kohara Y. 2006. Protocols for large scale in situ hybridization on C. elegans larvae. In WormBook (ed. The C. elegans Research Community). http://www.wormbook.org.

Motohashi T, Hirono K, Kohara Y. 2015. In situ hybridization on whole mount embryos of C. elegans. In WormBook (ed. The C. elegans Research Community). http://www.wormbook.org.

Pall GS, Codony-Servat C, Byrne J, Ritchie L, Hamilton A. 2007. Carbodiimide-mediated cross-linking of RNA to nylon membranes improves the detection of siRNA, miRNA and piRNA by northern blot. Nucleic Acids Res 35: e60.

Pena JT, Sohn-Lee C, Rouhanifard SH, Ludwig J, Hafner M, Mihailovic A, Lim C, Holoch D, Berninger P, Zavolan M, et al. 2009. miRNA in situ hybridization in formaldehyde and EDC-fixed tissues. Nat Methods 6: 139-141.

Reinhart BJ, Slack FJ, Basson M, Pasquinelli AE, Bettinger JC, Rougvie AE, Horvitz HR, Ruvkun G. 2000. The 21-nucleotide let7 RNA regulates developmental timing in Caenorhabditis elegans. Nature 403: 901-906.

Renwick N, Cekan P, Masry PA, McGeary SE, Miller JB, Hafner M, Li Z, Mihailovic A, Morozov P, Brown M, et al. 2013. Multicolor microRNA FISH effectively differentiates tumor types. J Clin Invest 123: 2694-2702.

Simon DJ, Madison JM, Conery AL, Thompson-Peer KL, Soskis M, Ruvkun GB, Kaplan JM, Kim JK. 2008. The microRNA miR-1 regulates a MEF-2-dependent retrograde signal at neuromuscular junctions. Cell 133: 903-915.

Sokol NS, Ambros V. 2005. Mesodermally expressed Drosophila microRNA-1 is regulated by Twist and is required in muscles during larval growth. Genes Dev 19: 2343-2354.

Sung HW, Chang WH, Ma CY, Lee MH. 2003. Crosslinking of biological tissues using genipin and/or carbodiimide. J Biomed Mater Res A 64: $427-438$.

Tabara H, Motohashi T, Kohara Y. 1996. A multi-well version of in situ hybridization on whole mount embryos of Caenorhabditis elegans. Nucleic Acids Res 24: 2119-2124.

Wienholds E, Kloosterman WP, Miska E, Alvarez-Saavedra E, Berezikov E, de Bruijn E, Horvitz HR, Kauppinen S, Plasterk RH. 2005. MicroRNA expression in zebrafish embryonic development. Science 309: 310-311. 

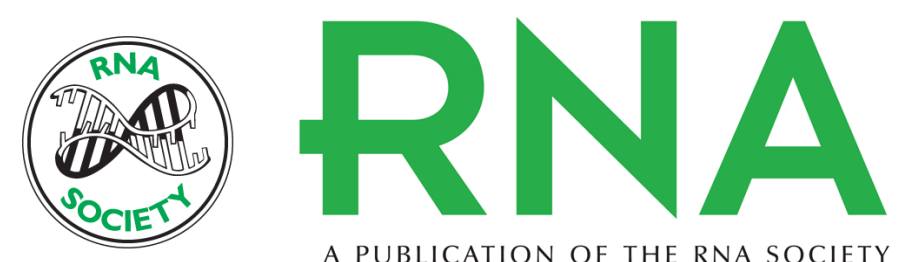

A PUBLICATION OF THE RNA SOCIETY

\section{A whole-mount in situ hybridization method for microRNA detection in Caenorhabditis elegans}

Yoshiki Andachi and Yuji Kohara

RNA 2016 22: 1099-1106 originally published online May 6, 2016

Access the most recent version at doi:10.1261/rna.054239.115

\section{Supplemental http://rnajournal.cshlp.org/content/suppl/2016/05/06/rna.054239.115.DC1 Material}

References This article cites 22 articles, 7 of which can be accessed free at: http://rnajournal.cshlp.org/content/22/7/1099.full.html\#ref-list-1

Creative This article is distributed exclusively by the RNA Society for the first 12 months after the Commons License full-issue publication date (see http://rnajournal.cshlp.org/site/misc/terms.xhtml). After 12 months, it is available under a Creative Commons License (Attribution-NonCommercial 4.0 International), as described at http://creativecommons.org/licenses/by-nc/4.0/.
Email Alerting Receive free email alerts when new articles cite this article - sign up in the box at the Service top right corner of the article or click here.

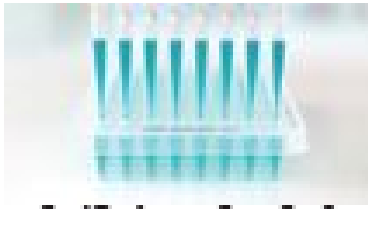

\section{Providing Precise Solutions for} your research.

To subscribe to $R N A$ go to:

http://rnajournal.cshlp.org/subscriptions 